\title{
Cidade: Uma análise psicossocial do espaço citadino após inundação ${ }^{\mathrm{I}}$
}

\author{
[ City: A psychosocial analysis of the urban space after floodings
}

\section{Leandro Roberto Neves ${ }^{2}$}

\section{Ianni Regia Scarcelli ${ }^{3}$}

RESUMO - Este texto é uma prévia conjugação analítica de uma primeira problematização da pesquisa intitulada Além da superfície: As produções das trincheiras espaciais simbólicas, que propõe estudar as relações dos citadinos com a cidade de São Luiz do Paraitinga (São Paulo, Brasil). Tais relações compõem as possíveis transformações na representação da imagem da cidade considerando o processo sócio-histórico da formação arquitetônica da cidade, assim como os aspectos simbólicos que permeiam e sofrem mediações conjunturais. Os elementos constitutivos do espaço representado na cidade foram intensamente friccionados em virtude de inundações ocorridas em I863 e na passagem do ano de 2009 para 20Io. Tais inundações provocaram, de forma semelhante, a destruição de edificações do centro da cidade e alagamento das áreas rurais, entre outras. Nesse sentido, parte-se de um contato etnográfico com o local e tem-se como referência um aporte teórico centrado em pressupostos da concepção de Lefebvre sobre como o espaço é qualificado pelo corpo e como a produção de representações subverte a realidade da imagem construída. Resultados parciais desta investigação indicam que a orientação da população para a reconstrução da cidade, após as inundações, está assentada em imagem institucionalizada da cidade, centrada no duplo real/aparente. • PALAVRAS-CHAVE • espaço; representação; inunda- ção - ABSTRACT - This text is a previous analytic version of a first problematization of the research, entitled Beyond the surface: The productions of the symbolic spacial trenches, which is intended to study the relations of the inhabitants with the city of São Luiz do Paraitinga (São Paulo, Brazil). Such relations contain the possible transformations in the representation of the image of the city, considering the sociohistorical process of the architectural formation of the city, as well as the symbolic aspects that appear and suffer conjunctural interventions. The constituent elements of the represented space in the city were, intensively, disturbed due to the floodings in 1863 and at the end of 2009 , beginning of 20Io. Such floodings caused in a similar form, a destruction of the buildings downtown and the flooding of the rural areas, at least. In this sense, starting first from a local ethnographic contact and a theoretical support centered on some presuppositions of the Lefebvre conception about how the space is qualified by the body, and how the production of representations subvert the reality of the built image. It was emphasized as a partial result of this research an orientation of the population for the rebuilding of the city, after that the floodings were established in an institutionalized image of the city centered on the dual real/semblance. - KEYWORDS - space; representation; floodings

Recebido em 25 de março de 2015

Aprovado em 07 de março de 2016

DOI: http://dx.doi.org/Io.II6o6/issn.23I6-90IX.voi63pI59-I80

I Este texto é uma versão revisada e ampliada do conteúdo apresentado na II Conferência do Desenvolvimento - IPEA, Brasília/20II e publicado na revista on-line Chão Urbano, em 20I2. O resultado completo da pesquisa encontra-se no livro: Psicossociologia urbana: Catástrofe socioambiental de enchente - Um estudo de caso. Curitiba: Juruá Editora, 2016.

2 Universidade Federal de Roraima (UFRR, Boa Vista, RR, Brasil).

3 Universidade de São Paulo (USP, São Paulo, SP, Brasil). 


\section{INTRODUÇÃo}

As relações que se estabelecem entre citadinos ${ }^{4}$ e sua cidade têm sido alvo de nosso interesse. Elegemos o município de São Luiz do Paraitinga para nossa investigação devido às suas características singulares e às mudanças ocorridas recentemente em função de catástrofes de origem natural que, provavelmente, trouxeram transformações na representação dos citadinos em relação à imagem da cidade. Sabemos que os elementos constitutivos do espaço representados nessa cidade foram intensamente friccionados em, pelo menos, dois momentos de sua história, em virtude de duas grandes inundações ocorridas, respectivamente, em I863 e na passagem do ano de 2009 para 2010.

Apesar de serem períodos históricos distantes, exatamente um decurso de I47 anos, os citadinos tiveram uma ação parecida após a catástrofe ambiental. Essa ação partiu de uma ideia coletiva de reconstrução imediata da cidade, a qual elegia como prioridade a reconstrução dos casarões no centro da cidade e no mesmo formato.

Essa representação dos casarões ou centro histórico teve em sua base elementos importantes para desvelamento da construção do espaço urbano. Ensejou a possibilidade de apontar como as produções materiais transformaram o espaço habitado e como a vivência desse espaço produziu camadas concretas e simbólicas, que se reproduziram secularmente. Em outros termos, deixou resíduos históricos submersos à percepção do aparente, do óbvio.

A reconstrução no mesmo formato poderia ser considerada natural, porque as edificações são legados de uma memória social, de uma cultura e de uma identidade. Contudo, podemos indagar sobre como isso aconteceu e como edifícios de ostentação e controle se transformaram em memória social. A fim de responder a essas indagações, foi interpolado um conjunto de reflexões sob a constituição do

4 No texto utilizaremos a nomenclatura “citadino” para nos referirmos aos habitantes de áreas urbanas, localizadas especificamente no centro e nos bairros em seu entorno. Contudo, pontualmente, utilizaremos a palavra "munícipe", a qual refere-se ao habitante do munícipio de São Luiz do Paraitinga, que envolve também as áreas rurais. Salientamos que, para Lefebvre (A revolução Urbana. 3. ed. Belo Horizonte: Editora UFMG, 2008), o tecido urbano não se restringe ao domínio da cidade, expande-se para o campo e cada vez mais o subordina. 
espaço urbano, buscando circunscrever como a população de São Luiz do Paraitinga transitou de um espaço prático/vivido, ou espaço de representação, para uma representação do espaço ${ }^{5}$. Para descrever essa passagem ou transição, faz-se necessária uma regressão histórica, explicitando contradições, demarcando o processo de colonização, as relações de poder e, sobretudo, anunciando a relação psicossocial com o espaço e deste como corpo habitado.

O texto se inicia com uma breve apresentação histórica da cidade e descreve o processo de colonização, suas bases produtivas, as características da cidade e os interesses ideopolíticos do Estado.

Na sequência, é apresentada a base conceitual da investigação, ressaltando-se a noção de espaço como lugar comum a todos, onde há várias experiências ocorrendo no mesmo tempo e de forma diferente, sendo o mesmo vivido e representado. As transformações produtivas constituem a base material do espaço, mas nele há também camadas imateriais, simbólicas produzidas na relação homem/ambiente.

Adiante, o texto traz uma interpolação reflexiva da análise histórica e da fundamentação teórica, buscando construir uma acepção da constituição do espaço social da cidade de São Luiz do Paraitinga. Elege-se o corpo como objeto de inter-relação homem/ambiente; a cidade, produto da criação humana, é uma extensão do corpo, logo o espaço da cidade é o espaço do corpo e das mediações que se estabelecem entre o sujeito psicológico e o objeto. É o corpo que dá vida à cidade, é ele que a produz e, portanto, corpo e cidade são indissociáveis ${ }^{6}$.

Da relação homem/ambiente a partir da noção de corpo como espaço, a argumentação caminha no sentido de estabelecer uma relação direta entre a experiência do espaço vivido e as edificações criadas para dar sustentação a essas experiências. $\mathrm{O}$ objeto concreto é representante simbólico das experiências imateriais. Naufragando o objeto material, desestabiliza-se o sustentáculo concreto da identidade cultural. É preciso, assim, recompor o objeto da memória social7.

Entretanto, a representação do espaço foi produzida, primeiramente, a partir da intervenção estatal no local. Tal ação planejada, arquitetada e estratégica no espaço citadino reconduziu, em alguns casos, a experiência do espaço vivido para uma esfera do controle político e econômico. Nesse cenário, as determinações estratégicas sobre o espaço tiveram o objetivo de nortear o comportamento da população, o hábito e ação dos citadinos. Dessa maneira, o espaço passou a ser concebido e representado como mercadoria de troca.

Assim, é no bojo desse processo dialético - vivência do espaço representado e representação do espaço - que as edificações foram piladas no imaginário. O objeto transformou-se em símbolo do urbano e redimensionou a percepção dos munícipes; a força prescritiva desses símbolos fomentou uma ação coletiva da reconstrução do centro da cidade e a manutenção da tradição.

As primeiras conclusões indicam que as esferas públicas, sabedoras da importância desses objetos para a memória social, investem na publicidade da

5 LEFEBVRE, Henri. La production de l'espace. Paris: Anthropos, I974.

6 CALVINO, Italo. As Cidades Invisíveis. São Paulo: Companhia das Letras, I972.

7 BOSI, Ecléa. Memória e Sociedade: Lembranças de velhos. I6. ed. São Paulo: Companhia das Letras, 2010. 
reconstrução, apropriando-se dos elementos simbólicos do imaginário popular. A formação da ideia da reconstrução está relacionada a uma estrutura social estabelecida no município que priorizou, nesses I47 anos, a manutenção da tradição em detrimento dos novos atrativos da sociedade urbana.

\section{Apontamentos históricos Da Cidade}

A cidade de São Luiz do Paraitinga está localizada na Serra do Mar, a cerca de duzentos quilômetros da capital paulista, entre as cidades de Ubatuba e Taubaté. Pode ser considerada uma típica cidade de interior brasileiro devido à sua característica arquitetônica e às práticas culturais e religiosas de seus munícipes. O município é reconhecido por possuir o maior conjunto arquitetônico construído nos tempos áureos do café, incluindo algumas fazendas que ainda permanecem conservadas.

O modo de vida local teve origem na sociabilidade e cultura caipira ${ }^{8}$, e ainda hoje permanece na cidade um estilo de vida carregado de significados culturais, que traduz uma tipologia regional e tipicamente brasileira, em contraposição às novas formas de expressão popular, produzidas pelo processo de consumo e entretenimento da sociedade de massa?.

O decurso histórico da cidade, segundo pesquisadores do local ${ }^{\mathrm{Io}}$, é marcado pelos ciclos de crises econômicas e políticas conjunturais que atravessaram o país e forjaram, na cidade, processos de desenvolvimento econômico e social centrados, principalmente, no poder político e religioso, cuja base se encontra na estrutura econômica de funcionamento do município.

Durante o século XVIII, houve maior controle da colônia portuguesa sobre o Brasil devido ao empobrecimento de Portugal. As revoluções ocorridas na Europa e a independência dos Estados Unidos da América fomentaram uma lógica mundial do livre comércio. Nesse contexto, as cidades brasileiras tornaram-se fulcros do controle

8 CANDIDO, Antonio. Os parceiros do Rio Bonito: Estudo sobre o caipira paulista e a transformação dos seus meios de vida. II. ed. Rio de Janeiro: Ouro Sobre Azul, 2oIo; BRANDÃO, Carlos R. Partilha da vida. São Paulo: Cabral Editora, I995; GONÇALVES, Bruno S. Na Travessia da Modernidade: Imaginação poética e resistência na memória de caipira em São Luiz do Paraitinga. Dissertação de mestrado. São Paulo: Pontifícia Universidade Católica, 2007. Para Candido, a característica geral da cultura caipira e sociabilidade se estruturou nos seguintes aspectos: "isolamento; posse da terra; trabalho doméstico; auxílio vicinal; disponibilidade de terras; margem de lazer" (CANDIDO, Antonio. Op. cit., p. 97).

9 ARENDT, Hannah. A crise na cultura: Sua importância social e política. In: . Entre o Passado e o Futuro.

6. ed. São Paulo: Perspectiva, 2007.

Io TOLEDO, Marcelo H. S. Espaços individuais e coletivos de sacralidade nos meios de populares: Um estudo sobre a imagem, conflitos simbólicos e campo religioso. Dissertação de mestrado. São Paulo: Pontifícia Universidade Católica, 200I; VIEIRA, Luis A. “Está chegando o tempo de política... de eleição...”: Expressões da participação política dos moradores do Distrito de Catuçaba, São Luiz do Paraitinga, SP - Permanências e mudanças”, 2007/2008. Dissertação de mestrado. São Paulo: Pontifícia Universidade Católica, 2008; SANTOS, João R. C. C. A Festa do Divino de São Luiz do Paraitinga: O desafio da cultura popular na contemporaneidade. Dissertação de mestrado. São Paulo: Universidade de São Paulo, 2008. 
estratégico da coroa portuguesa. São Luiz do Paraitinga foi fundada nesse período de tensão política e de ações estratégicas da coroa portuguesa, cujo intuito maior era controlar o território nacional.

Dessa forma, o agenciamento econômico do local pela instância pública pode ser percebido no percurso histórico e econômico da cidade e sua base econômica parece ter-se constituído, inicialmente, a partir de um lugar de passagem e entreposto. A Vila, antes de se constituir como cidade, tinha importância para as tropas que transportavam ouro de Minas Gerais para o porto de Ubatuba (SP). Em um segundo ciclo econômico, a monocultura cafeeira estabeleceu-se como a principal forma de produção e, posteriormente, com a decadência do café, destacou-se a agropecuária, com ênfase na produção de leite. Atualmente, sua economia está centrada, principalmente, na monocultura de eucalipto e no investimento ao turismo, caracterizando-a, mais recentemente, como uma cidade que transita da produção agromercantil para a produção turística.

Pelos registros históricos, pode-se supor que a introdução de um espectro econômico nos moldes pré-capitalistas no local ocorreu na transição de povoado para Vila e, posteriormente, para cidade. É possível afirmar que nessas passagens, houve uma ingerência da estrutura estatal, primeiramente do Império português e depois da República, sobre o modo de vida rústico ${ }^{\mathrm{II}}$ em que se encontravam os seus habitantes.

O colonizador, para promover o desenvolvimento urbano do povoado a partir de interesses econômicos e políticos, impôs um processo de transformação do espaço, o que analisaremos mais adiante. Mas importa destacar aqui que a primeira ação imposta foi a instituição de um poder estatal local de controle administrativo, econômico, político e religioso, que fixava a população habitante dos sítios volantes em áreas predeterminadas e arruadas em torno do centro político e administrativo.

Tal imposição concentrava a população em um lugar, o que permitia fluidez econômica do comércio; instituía um centro de orientação geográfica, administrativa, política, econômica; e fomentava, embrionariamente, a formação da cidade. Desta forma, o colonizador foi progressivamente implementando um sistema administrativo estatal de controle da arrecadação dos impostos e do espaço citadino.

Antes dessa ação, tinham-se poucas informações e, consequentemente, pouco controle acerca do número de propriedades locais, da procedência dos proprietários e da regulamentação jurídica da propriedade privada. Ou seja, a coroa não sabia de quem cobrar e quanto cobrar. Segundo Trindade, o processo de colonização portuguesa em São Luiz do Paraitinga, pautado no ideário iluminista, "orientou um empirismo geográfico do sítio escolhido, da topografia e do rendimento imediato da instalação"ז2. Os edifícios concentrados nos lugares escolhidos tinham uma simetria no padrão arquitetônico e serviam como objeto de controle e direcionamento. Eram tributados e funcionavam como emblemas de um segmento econômico da cidade e

II CANDIDO, Antonio. Op. cit.

I2 Trindade, Jaelson B. No caminho do Paraitinga. In: TRINDADE, Jaelson B. Luis e SAIA, Luis. São Luiz do Paraitinga: Publicação n. 2 do Conselhos de Defesa do Patrimônio Histórico, Arqueológico, Artístico e Turístico do Estado. São Paulo, I977, p. 22. 
somente os representantes do poder público e as famílias abastadas tinham condições de morar naquele espaço demarcado.

Para a construção das primeiras edificações públicas, foram projetados no terreno da praça os edifícios públicos (Casa da Câmara e Cadeia) e uma igreja. "Assentou-se, na cerimônia de instituição da Vila, o pelourinho, emblema de potestade e governo, emblema de potestade ou força - conjugando as autoridades laica e religiosa. "I3

Demarcado o centro a ser construído, assim como a topologia das edificações, iniciou-se a formação do centro urbano da cidade e seu entorno. Na área baldada ao redor da praça, de forma contígua, foram construídos casarões seguindo um modelo arquitetônico mineiro e português. Tais construções ocorreram com maior vulto no período do café, expressando o poder político, econômico e religioso dos fazendeiros, dos políticos e dos comerciantes ricos da cidade.

\section{APResentando conceitos}

Partimos de uma concepção do espaço como lugar comum ${ }^{\mathrm{I} 4}$ em que ocorrem as práticas sociais e onde se vive, se comunica e se inter-relaciona. Um lugar da coexistência da heterogeneidade $e^{15}$, da pluralidade das ações humanas e onde se estabelece a relação com o ambiente. Nessa concepção, o espaço não é vazio nem apenas superfície; ele é composto de historicidade, forma e conteúdo que se forma na infinita rede de relações do homem, da natureza e das produções materiais e imateriais.

Para Lefebvre, na prática social o espaço pode ser apropriado prático, concebido $e$ vivido, constituindo camadas a serem apreendidas empiricamente ${ }^{16}$. Contudo, no plano do pensamento, o espaço diz respeito à produção de conceitos, a uma abstração do real. Nessa perspectiva, Bachelard (2000, p.88) comenta que "os conceitos são gavetas que servem para classificar o conhecimento"ı7, e propõe uma abordagem centralizada na imaginação poética que se define como uma forma diferente de se ver o mundo, rompe com a objetividade e se revela a uma luz íntima (alma).

É na relação da prática social, com as experiências simbólicas derivadas da apreensão subjetiva do concreto, que buscaremos compreender como a população de São Luiz do Paraitinga transitou de um espaço prático/vivido para uma representação do espaço, considerando que na trajetória histórica das produções materiais o espaço se caracterizou como matéria (edificações) e símbolo (cultura).

Nesse trânsito em constante tensão, irrompem no imaginário do citadino formas de resistência, relação de afeto com o lugar, demarcando à cidade particularidades no que se refere à cultura e a forma de enfrentamento da inundação provocada pela

I3 Idem, p. I2.

I4 BETTANINI, Tonino. Espaço e ciências humanas. Rio de Janeiro: Paz e Terra, I982.

I5 MASSEY, Doreen. Pelo espaço: Uma nova política da espacialidade. Rio de Janeiro: Bertrand Brasil, 2008.

I6 LEFEBVRE, Henri, Op. cit., I974.

I7 BACHELARD, Gaston. A poética do espaço. São Paulo: Martins Fontes, 200o, p. 88. 
enchente. Contraditoriamente, o elemento cultural dessa resistência corre o risco de ser, parcialmente, manipulado de acordo com os interesses políticos e econômicos.

Faz-se necessário também explicitarmos a noção de cidade que nos orienta, considerando a diversidade de conceitos nessa perspectiva. Apropriamo-nos da concepção sociológica de Lois Wirth (I967), que concebe cidade como núcleo concentrado de pessoas heterogêneas, no qual é instituída uma centralidade administrativa e política. No caso de São Luiz do Paraitinga, além dessa centralidade, constata-se, ainda como permanente, uma dicotomia entre áreas citadinas: urbano e rural.

Situadas tais noções, uma pergunta nos mobiliza: como entender a questão do espaço em uma cidade parcialmente destruída pela chuva?

\section{A CONSTITUIÇÃO DO ESPAÇO}

Para iniciar essa discussão tomemos dois acontecimentos:

\section{Primeiro momento - Natal, 1863}

O natal de I863, em São Luiz do Paraitinga, é um drama ribeirinho: as águas enlouquecidas do Paraitinga sobem até bem perto da porta da igreja matriz [...] ruem a cadeia, os sobrados do capitão Bento Domingues de Castro, do tenente-coronel José Domingues de Castro e um ainda do finado Jerônimo Ramalho de Campos São Tiago [...], além de muitos outros seriamente abalados e inundados. As águas são violentas, rolam a ponte velha e tudo o que já estava montado para a ponte nova, juntamente com todos os muros, confundindo líquida, pastosa e afinal polvorentamente, as fronteiras sociais do núcleo urbano de São Luiz do Paraitinga. [...] Como há males que vêm para o bem, o correspondente aplaude a decisão dos arruinados que pretendem reedificar seus sobrados nos mesmos lugares, mas agora com pilares de pedra; e sugere que se reedifique a Cadeia, rapidamente, como é natural, em local mais salubre; no seu lugar poder-se-ia se instalar a Quitanda (o mercado) [...] ${ }^{\mathrm{I}}$.

\section{Segundo momento - Réveillon, 20ro}

A cidade é uma estância turística e tem como principal característica a preservação de construções históricas, como casarões e igrejas cuja data de edificação se conta em séculos. Na enchente, grande parte disso se perdeu. [...] Pouco mais de três meses após o ocorrido, São Luiz do Paraitinga começa a se reerguer. Em uma rápida caminhada pela cidade se vê um bom número de profissionais atuando para reconstruir, restaurar e fazer nascer de novo parte do que foi perdido por conta da inundação ${ }^{\text {I9. }}$

I8 ALMEIDA, Jaime de. Foliões: Festas em São Luís de Paraitinga na passagem do Século (I888-I9I8). Tese (Doutorado). São Paulo: Universidade de São Paulo, I987, p. 455.

I9 Disponível em: <http://www4.usp.br/index.php/especiais/I880o-meses-depois-da-tragedia-paraitinga-sereergue-e-tem-a-usp-como-aliada $\rangle$. Acesso em: 05 de agosto de 2010 
[...] A prefeita [...] explica que a tragédia não fará com que São Luiz do Paraitinga reveja sua vocação econômica. "Seguiremos investindo no turismo, que é o que movimenta a cidade" $[. . .]^{20}$.

\section{I863: PRIMEIRO MOMENTO}

O primeiro acontecimento demonstra a destruição de algumas edificações construídas no entorno da praça em I863. As casas ou edificações públicas, naquele momento, não tinham a representação que se tem hoje de patrimônio histórico. $\mathrm{O}$ jornalista, conforme trecho destacado, deixa claro que a inundação misturou as fronteiras sociais até então demarcadas no espaço através da localização e do valor econômico atribuído a tais edificações.

Para compreendermos refletidamente sobre esse primeiro processo de construção de fronteiras no espaço desse município, tomemos a noção de espaço como corpo. A emersão da imagem do corpo se reproduz na cidade ${ }^{21}$. O espaço citadino se apresenta visivelmente como uma entidade autônoma ao corpo, mas esse espaço sobrepõe camadas não visíveis. Tais camadas, produto das relações dos corpos, têm em si os afetos, as histórias, os traçados, a cultura e a poética que compõem um cenário imaginário das ruas, das casas, da praça. O corpo está inserido na cidade, os quais são indissociáveis, se expressam na arquitetura, no urbanismo e no invisível da cidade ${ }^{22}$.

Pensar no corpo é pensar em um espaço vivo, atuante, autotransformador e transformador de outros espaços, que podem ser animados e inanimados, e também objetos. Para Bettanini, baseado nas ideias de Merleau-Ponty, a experiência do corpo ou imagem corporal ensina a enraizar o espaço na existência ${ }^{23}$. Assim, não há espaço sem corpo e corpo sem espaço; mundo e corpo estão interligados.

Segundo Lefebvre, o discernimento do espaço é possível com a introdução de eixos de orientação e direção engendrados pelo corpo, o qual ocupa o espaço24. $\mathrm{O}$ termo ocupação é usado no sentido de uma relação imediata entre espaço e corpo. $\mathrm{O}$ autor introduz uma discussão do corpo vivo como espaço, o qual produz e se reproduz no espaço. Para ele, o corpo age sobre a matéria transformando-a, produz seu alimento para se sustentar (produz seu próprio corpo) e se reproduz pela parceria com um outro corpo. Então, temos o corpo vivo operando no espaço e o espaço concreto (natureza) operando no corpo.

Tomando como escopo a cidade, podemos inferir que esta é um corpo vivo, pois os corpos funcionam como matriz do espaço da cidade, dando-lhe vida. Não há cidade

\footnotetext{
20 Disponível em: $\langle$ http://www4.usp.br/index.php/especiais/I880I-o-recomeco-da-cidade $>$. Acesso em: 05 de agosto de 2010

2I SENNETT, Richard. Carne e pedra: O corpo e a cidade na civilização ocidental. 4. ed. Rio de Janeiro: Record, 2006.

22 CALVINO, Italo. Op. cit.

23 BETTANINI, Tonino. Op. cit.

24 LEFEBVRE, Henri. Op. cit., I974.
} 
sem vida; quando desaparece a vida da cidade, esta se transforma em ruína. Então, os corpos dão vida e orientam a cidade, assim como a cidade, com vida, irradia no corpo: "A forma da cidade dá-lo à cidade. Sim, mas o que dá forma a essa forma é o ser humano. Assim, é o ser humano que dá o seu ser para a cidade”25.

Essa relação do corpo com o espaço citadino pode se dar de forma imediata ou mediata. Imediata, quando a experiência do espaço se restringe à sensação provocada pelos órgãos dos sentidos. Por exemplo, sentir o vento, o frio, a natureza, a música, a casa e outros elementos que irrompem uma sensação particular de integralidade, uma vivência do espaço, o qual não se apresenta para a consciência à dicotomia, interno e externo e/ou corpo e espaço.

Portanto, vive-se na cidade e a cidade está no corpo; tem-se uma fusão entre corpo e cidade. Esse tipo de integralidade configura-se, como salienta Pankow ${ }^{26}$, em um espaço vivido, utilização plena do espaço através da harmonia e integração com o mesmo, "onde há um arcabouço de significados, que passam a ser significantes na relação com o outro. Tal fato se desempenha pelo compartilhamento e pelas trocas simbólicas”27. O corpo é espaço em si e produtor do próprio espaço.

Assim, a relação de forma mediata sofre o efeito da decodificação, interpretação, racionalização e valorização, as quais muitas vezes fragmentam a experiência do vivido, a integralidade do espaço. As fragmentações são as dicotomias entre sujeito e objeto, indivíduo e meio ambiente, corpo e mente, entre outras divisões que, na vida cotidiana, alteraram a visão de mundo das pessoas.

É através dessa lógica dicotômica que o espaço, como um corpo, passa a ter diferenciações, interpretadas no senso comum como naturais. À guisa de exemplo, aqueles que moravam na parte baixa da cidade eram representantes do poder político, religioso e econômico; aqueles que moravam na parte alta eram o segmento menos abastado da cidade. Alegoricamente, é a esse respeito que o jornalista quis se referir quando comentou que a catástrofe em I863 rompeu as fronteiras sociais. Pareceram implícitas, no discurso, as demarcações concretas no espaço social, ou seja, presença da contradição socioespacial.

Por conseguinte, a mediação perpassou pela linguagem, religião, cultura, ideologia, política, ciência e outros. Houve uma interposição de algo entre o corpo e a experiência, entre o que é interno e externo, entre o homem e a natureza.

Devemos ressaltar que existem experiências mediatizadas que superam a fragmentação. Entretanto, para fundamentar a argumentação do espaço como corpo e sua divisão, nos apropriamos do pensamento de Lefebvre, o qual traçou o seguinte percurso:

I. A ocupação do espaço deve ser compreendida na sucessão das operações produtivas. Dessa forma, a noção de natureza é transformada, pois o espaço não é

25 BERQUE, Augustin. “Urbs Dat Esse Homini!” La trajectivité des formes urbaines. Conférence donnée au colloque Paisagem e arte, São Paulo, 6 septembre I999. In: ANGOTTI-SALGUEIRO (dir.). Paisagem e arte/ Paysage et art/ Paisaje y arte/Landscape and art. São Paulo: Comitê Brasileiro de História de Arte, 2000, p. 42.

26 PANKOW, Gisele. O homem e seu espaço vivido. Campinas: Papirus, I988.

27 NEVES, Leandro R. As trincheiras espaciais simbólicas: Circunscrevendo as políticas públicas habitacionais no Vale do Paraíba-SP. Anais do XIV Encontro Nacional da Abrapso, 2007. 
fruto de uma ordem divina ou matemática, mas das formas materiais de uma ocupação do espaço. Portanto, na relação natureza-espaço não há mediação de uma potência externa à lei do espaço; ela está no espaço.

2. O espaço é qualificado pelo corpo. Os elementos constitutivos do próprio corpo - produção, autoprodução e reprodução - agem de forma unificada sobre o espaço e no espaço.

Por sua vez, o corpo vivo está diante de outro corpo simétrico, o não Eu. E este não Eu (outro corpo) servirá de referência para o norteamento da ação do Eu e do Outro. Assim, estabelece-se uma relação de afirmação ou negação do Eu e do Outro, ou seja, o corpo-espaço se assemelha e se diferencia do Outro (corpo-espaço). Nessa lógica, temos uma relação dual dos corpos entre igualdade e diferença, simetria e dessimetria em constante tensão e movimento dos corpos no espaço. Assim, o corpo (uno ou inteiro), ao se sentir ameaçado ou favorecido pelo Outro, qualifica o espaço de acordo com seus elementos constitutivos (órgãos, tempo e sentidos). $\mathrm{O}$ tempo do corpo (crescer, amadurecer e envelhecer) não se separa da espacialidade.

Para esse autor, o corpo e o Eu são um único elemento que age de forma integral na relação com o Outro (corpo). Dessa forma, se o corpo é uno, então o espaço também o é, pois, o corpo é o próprio espaço, assim como a cidade. Mas elementos de mediação utilizados de forma estratégica fragmentam e hierarquizam o espaço, ou seja, o corpo e a cidade.

Para ilustrar esse processo, retomemos a intervenção pública no povoado. Tinha-se um povoado organizado a partir das heranças indígenas e costumes remanescentes das expedições bandeirantes. A fusão dos costumes, comportamentos, valores e outros aspectos promoveu, naquele povoado, um modo de vida típico para o local. Após uma intervenção direta do poder estatal sobre ele, mudaram-se as casas, expulsou-se os habitantes da terra, desenvolveu-se comércio, instituíram-se representantes diretos do poder, ou seja, foi totalmente alterada a característica do espaço, produzindo o espaço urbano.

Pois bem, essa intervenção não ocorreu de forma desarticulada e despretensiosa, mas intencional, pautada em uma estratégia da coroa portuguesa de cunho ideológico e político-administrativo. Assim, o conteúdo da ideia da intervenção amparou-se nas mediações estabelecidas pela linguagem, cultura, política e outros elementos sociais do colonizador. Não foram incluídas na concepção de mundo e, portanto, do espaço habitado às experiências ocorridas naquele lugar, prevalece uma visão de espaço como superfície desprovida de historicidade. Na efetivação de novos modelos produtivos, construíram um espaço que pudesse amparar as transformações na estrutura social em formação.

O sistema produtivo, ao mesmo tempo que trazia a sugestão de uma vivência urbana apoiada em princípios e valores do poder civil emergente, promovia diariamente o ataque mais impiedoso aos recursos naturais do território, contribuindo para sólida, se não irreversível, separação entre cidade e natureza, cujas consequências moldam ainda hoje as feições de nosso cotidiano urbano ${ }^{28}$. 
Após esse fato, outras experiências foram sendo sobrepostas às anteriores, formando camadas invisíveis na cidade, produzindo costumes, comportamentos, valores. No plano concreto, a produção da cidade se orientou pela visão de mundo do colonizador e esse construiu edificações, hierarquizou os lugares, dividiu o trabalho, desenvolveu novas formas de produção, marcou no corpo a divisão da cidade.

Diante disso, como fica o corpo a partir de uma inundação do espaço da cidade? Ocorre uma despersonalização do corpo?

No apontamento acima, estão ausentes produções materiais que decorreram de um processo histórico anterior à colonização. Por exemplo, as comunidades indígenas que lá viviam em uma relação integrada ao espaço, e que essa análise não abordou. Partindo de uma segunda etapa do processo de colonização portuguesa, evidencia-se que a relação estabelecida pelos habitantes com o espaço-corpo revelou um processo de subsistência desse corpo em uma sociedade dita "civilizada", introduzido através do ensino religioso e da força. O modo de vida, os costumes, a religião e a linguagem dos portugueses intercambiaram com a de outros povos no Brasil, mas de forma hierárquica. Pode-se dizer que o corpo (uno e intersubjetivo), na relação com outros corpos (inter-relação), sofre mediações (políticas, ideológicas, culturais) que nortearam as produções materiais e a formação cultural.

Nessa conjuntura, a população do local baseava-se na relação provinda do cultivo da terra, nas relações de parentesco, no trabalho doméstico, no lazer e na convergência religiosa com predomínio do catolicismo. Assim, corpo e casa estavam dentro de um arcabouço simbólico, construído a partir da vivência com a terra, com a religião, com a família.

A experiência dos corpos e/ou espaço vivido produziu representações, as quais envolviam a forma de habitar, as relações de poder, as práticas religiosas e outros elementos simbólicos que se concretizavam na temporalidade da vida simples daquelas pessoas. Uma vida centrada na tradição, no compartilhamento e no uso da terra. As mediações do corpo com o espaço envolviam a utilização dos sentidos, da linguagem, da energia do corpo no ambiente e nos outros corpos, a partir da perspectiva da finitude do corpo e das bases materiais.

Nesse cenário, essas representações dizem respeito ao que estamos denominando de espaço de representação $0^{29}$, ou seja, determinadas mediações que circunscreviam no imaginário o espaço do sagrado, relação de gênero, as crenças, os valores, os rituais e a proeminência católica, formando uma linguagem particular da comunidade.

Todavia, o espaço de representação produzido na experiência do vivido transcendeu a lógica de pura apropriação do outro e da natureza. Transitava em estado ontológico ${ }^{30}$, um estado de fermento ao imaginário citadino, propulsor de camadas invisíveis às imposições das práticas colonizadoras.

No espaço vivido houve a proeminência de uma relação de uso do espaço em contraste com uma relação de troca. Mesmo o local servindo como passagem de tropeiros (transportadores de ouro), as incipientes relações comerciais não se sobrepunham ao modo de vida singular de cultivo da terra daquela população. As

29 LEFEBVRE, Henri. Op. cit., I974.

30 BERQUE, Augustin. El pensamiento paisajero. Madri: Biblioteca Nueva, 2009 (Colección Paisaje y Teoría). 
relações eram imbuídas pelo sincretismo religioso, legado da catequização jesuítica, da cosmologia ameríndia e depois africana.

Podemos nos apropriar da reflexão de Sennett quando faz formulações acerca da relação do corpo com a cidade no mercantilismo na Europa ${ }^{3 \mathrm{I}}$. Ele parte do pressuposto de que a devoção cristã provocou uma cisão entre o mundo terreno e mundo de Deus; na terra, os cristãos precisavam abdicar dos seus desejos carnais, mesquinhos, ambiciosos, circunscritos ao corpo. E deviam fazer isso porque esse corpo não lhes pertencia, e, sim, a Deus.

O corpo passa a ser utilizado como objeto de martírio, de sofrimento, para ser purificado. Essa lógica busca semelhança com a trajetória de Cristo, repassada através de uma narrativa acabada. A história de Cristo teve começo, meio e fim. Seu ápice foi a mutilação do corpo como símbolo de superação da dor para encontrar o criador e purificar os mundanos. O sofrimento promovia a aproximação com o criador.

Os cristãos, com o tempo e após o sacrifício da carne, sentiram-se mudados, mas careciam de um lugar na terra que apontasse uma direção que não fosse apenas aquela após a morte (de finitude). Nesse cenário, o sentido econômico estava desvencilhado do religioso, pois o lugar cristão na terra baseava-se na compaixão; no revés, o desenvolvimento do comércio se assentava em um tempo econômico, buscando cada vez mais espaço de troca. Essa relação era agressiva, pois o que interessava era a lucratividade no comércio.

Instalou-se, portanto, um processo de contradição entre os católicos, manifesto na cisão entre lugar e espaço, oportunidade e estabilidade, piedade e atitudes hostis. Como, então, buscar um lugar de compartilhamento e compaixão se as atividades do comércio buscavam o seu contrário? Essa questão do catolicismo na Europa, com as devidas ponderações, pode ser pensada na cidade de São Luiz do Paraitinga. Como conjugar a experiência da terra, da comunhão, da troca, do sincretismo religioso, com um mundo que impunha um ordenamento centrado nas condições comerciais, a primazia do econômico?

Nesse trajeto da reflexão é que é possível responder à relação da primeira enchente com a população, pois entendemos que estavam vivenciando, na época, um tipo de conflito semelhante a esse.

As missões jesuíticas no Brasil reproduziram, através da catequização, ensinamentos da história de Cristo, os quais foram amalgamados às experiências de outros povos que aqui habitavam, formando um sincretismo religioso no povoado de São Luiz do Paraitinga. Houve um predomínio da Igreja católica sobre as demais experiências religiosas.

Consequentemente, a experiência com o sagrado e com a terra produziu os espaços de referência, espaços de sentido para o modo de vida da cidade. Tais espaços de representação possibilitaram à população um apego ao lugar, atravessado pelo pertencimento, identificação, afeto, religiosidade com o espaço (corpo e pedra), que nos remete à experiência do vivido "viver o espaço significa senti-lo em primeira

3I SENNETT, Richard. Op. cit. 
pessoa”32, se referir ao corpo, a suas necessidades elementares a traduzir um mundo nos outros.

Temos, como hipótese, que a praça da igreja matriz, os casarões e o mercado são alguns dos espaços de representações produzidos na cidade, pois pudemos constatar sua permanência e relevância na vida dos citadinos, após mais de um século da primeira grande enchente.

Em tais espaços de representações, permanecem as realizações das festas populares tradicionais, existe um constante fluxo de pessoas transitando e conversando, percebemos que tais objetos são usados como referência para orientação no espaço geográfico da cidade, ponto de referência espacial. São espaços com elementos simbólicos locais de sociabilidade; de comércio; de religiosidade; de cultura; de historicidade; ou seja, um espaço do compartilhamento das experiências cotidianas da memória social33, da topofilia34.

A inundação destruiu pela primeira vez o centro da cidade, espaço apropriado comercialmente ou domiciliarmente pelo segmento abastado da cidade. Como esse espaço estava inscrito no imaginário do citadino, emerge um desejo coletivo de reconstrução que transcende as fronteiras sociais. Os pobres da cidade se solidarizaram com a perda do outro, pois compartilharam a dor e ajudaram na reconstrução. Essa ajuda teve um caráter simbólico, pois contribuiu para a permanência do sentido que a cidade tinha para o corpo e o corpo para a cidade, pois o que subsistiu após a tragédia são os elementos invisíveis brotados no espaço vivido, os quais estavam marcados no corpo de cada citadino.

Destruir aquilo que representa, parcialmente, a cidade, possibilita uma desconstrução da imagem e do sentido da cidade e da vida para os próprios citadinos. Entretanto, o espaço de representação fomentou um sentimento de compaixão e um lugar de compartilhamento. A destruição das edificações não destruiu o invisível da cidade. Pelo contrário, criou-se força para uma reconstrução.

\section{RÉVEILLON DE 2OIO: SEGUNDO MOMENTO}

Progressivamente, a racionalidade capitalista do colonizador foi sendo impingida na visão de mundo da população, fragmentando o espaço em lugares hierarquizados e hierarquizando os corpos. O processo da apropriação privada e mercantil do espaço, intensificado no século XIX, engendrou espaços vazios de sentido e os transformou em espaços cindidos de consumo. Ora, as relações comerciais se apropriaram do imaterial, ora o imaterial resiste no imaginário como substrato de resistência ao novo ordenamento da modernidade.

32 BETTANINI, Tonino. Op. cit., p. II4.

33 BOSI, Ecléa. Op. cit.

34 TUAN, Yi Fu. Topofilia: um estudo da percepção, atitudes e valores do meio ambiente. Londrina: Eduel, 2012. 


\section{Como isso aconteceu?}

Nossa hipótese é a de que o colonizador introduziu um projeto de modernização das relações comerciais que se relacionava com a conjuntura política e econômica da Europa no século XIX. Estrategicamente, foi construída uma igreja e dois órgãos públicos com o intuito de legitimar um ordenamento institucional da estrutura social. A edificação da igreja pode ser analisada como a concretude do poder religioso; a edificação da cadeia, como a concretude da força da lei, da justiça, do controle. E, a edificação da Casa da Câmara, como imponência concreta do poder político.

Ato contínuo, essas três edificações demarcavam uma transição no tempo e no espaço, pois o espaço vivido/espaço de representação passa a sofrer uma ingerência da organização racional do espaço comandado por centros concretos de poder. Constituía a esfera do político (do grego polis, cidade) estruturada em um estatuto jurídico e comandada pelos representantes locais da entidade social, o Estado35.

Nesse sentido, o domínio da cidade pelo Estado, fomentou transições nas relações sociais e nos modos de produção, subordinando o espaço vivido/espaço de representação $0^{36}$ para a representação do espaço, ou seja, a cidade passa a ser planejada de acordo os interesses e visão de mundo do colonizador. Primeiro se planeja a topografia, as ruas, as casas, seguindo um ordenamento geométrico, para depois se construir. Primeiro se esquarteja o espaço em um projeto, para depois concretizar. Esse processo instigou uma fragmentação do simbólico, do concreto. "A ordem institucional atribui ao espaço sagrado e/ou espaço de representação a função de objetivar, na pedra, um corpo de tradição cujo significado se diferencia radicalmente do da vida quotidiana." ${ }^{37}$

A estratégia do colonizador, naquele contexto, denotou transformar o espaço vivido em espaço qualificado economicamente, um espaço organizado e administrado pelo poder político e econômico. Os lugares na cidade passaram a ter valor de troca, de acordo com o planejamento do espaço. Esse planejamento do espaço, orientado pelo saber técnico, engendrou lugares e objetos com status diferenciados, produzindo uma hierarquia dos lugares na cidade.

Tais lugares, objetos e situações "fabricados" configuram uma inversão no uso do espaço. Tínhamos um espaço que propiciava representações para agora termos representações que propiciam o espaço - qualquer lugar na cidade passa a ter um valor de troca e não mais de uso; há uma estratégia, um planejamento. Podemos constatar que a tipologia arquitetônica foi um dos recursos técnicos para prescrever

35 WUNENBURGER, Jean-Jacques. Imaginário e política. In: ARAÚJO, A. F. e BAPTISTA, F. P. (orgs). Variações sobre o imaginário: Domínios, teorizações e práticas hermenêuticas. São Paulo: Instituto Piaget, s.d.

36 Para Lefebvre, existe uma tríade para compreender a produção social do espaço, a qual ele denomina de percebido, concebido e vivido. Esses conceitos correspondem, na análise espacial, a prática do espaço (percebido na relação imediata com o corpo), representação do espaço (concebido pela abstração do real através da lógica e mediado pelas ideologias) e espaço de representação (vivido através das imagens e símbolos produzidos nas experiências do uso do espaço habitado, sofre as mediações da linguagem, cultura, religião) (LEFEBVRE, Henri. Op. cit., I974).

37 BETTANINI, Tonino. Op. cit., p. 96. 
o poder econômico. Atualmente, as edificações se tornaram signos das instituições e das relações de força do poder político, econômico e religioso.

Considerando essa constatação, postulamos que objetos materiais, até então desprovidos de sentido, tornam-se representações carregadas de significados, os quais assumem uma dimensão ímpar na vida das pessoas. A imagem das edificações tem uma função prescritiva no espaço social: elas se tornam o espaço, a vida, as pessoas. Sem elas, fica inconcebível a formação da cidade. Parece que ela se torna o sujeito da história e subordina toda a existência humana que houve ali em uma história dela mesma.

Para ilustrar essa reflexão, relembramos uma conversa com um colega, frequentador assíduo de São Luiz do Paraitinga, questionado a respeito da reconstrução das edificações no mesmo lugar. Para ele, era inconcebível que os casarões fossem construídos em outro lugar: não seria mais São Luiz do Paraitinga.

Ou seja, o quanto os objetos socialmente valorizados prescrevem as nossas imagens e ofuscam a história. A cidade não se restringe apenas ao centro, mas em determinado período histórico, o centro (urbano) assume o lugar da troca, do econômico, da ostentação, do controle dos corpos que "valiam" mais. Pois era palco dos políticos, dos fazendeiros, dos comerciantes ricos, da igreja. Era um lugar aberto a todos citadinos, mas reservado ao domínio de uma minoria.

As edificações estavam piladas no imaginário, o objeto transformou-se em símbolos do urbano e redimensionou a percepção desses munícipes, como pode ser extraído desta passagem:

[...] a urbanização significa a estrutura da vida comum, na qual a diversidade e a desintegração da tradição são proeminentes. Significa uma impessoalidade em que as relações funcionais se multiplicam. Significa que um grau de tolerância e de anonimato substitui as sanções morais tradicionais e as convivências de longa duração. O centro urbano é o lugar do controle humano, do planejamento racional, da organização burocrática [...]. Quando o homem muda os seus meios de produção, seus instrumentos e distribuição de bens também mudam os seus deuses [...] ${ }^{38}$.

E o que pode ser percebido na segunda inundação? A reconstrução assemelha-se ao processo da primeira, com algumas diferenças: agora não será mais feita pelos agentes da cidade e será preciso um saber técnico externo, pois a técnica de construção, atividade comum no período colonial, caiu em desuso na vida moderna. Além disso, os ciclos produtivos do município (café, gado, leite) alteraram a relação da população com a cidade, que agora tem, entre as suas bases econômicas, o turismo histórico; perdê-lo é perder o seu encantamento e uma das fontes econômicas.

Percebemos, também, o uso político da enchente. Todos os esforços se concentram na construção do simulacro e na representação da reconstrução do centro histórico, e não, por exemplo, no tratamento de saúde dos desabrigados que adoeceram devido à perda de seu imóvel e da despersonalização que isso representa. Através das entrevistas e observações locais, percebemos, de forma recorrente, os citadinos

38 COX, Harvey. A cidade do homem. 2. ed. Rio de Janeiro: Paz e Terra, I97I, p. I5-I9. 
atrelarem o falecimento de pessoas idosas pós-enchente às perdas ocasionadas pela inundação, principalmente a do imóvel.

As edificações, construídas em grande parte no período da cafeicultura, transformaram-se no símbolo do próprio período, objeto da memória social. Essas incorporaram ao seu signo a ideia da tradição. Dessa forma, a imagem das edificações transladou da perspectiva individual do ente privado para uma perspectiva social de um ente público. Passou a representar toda a cidade e o conteúdo dessa imagem é uma ideia da tradição, da cidade tradicional. Mesmo no percurso histórico, emergindo outros símbolos representantes da cidade, as edificações construídas no período do café são as que mais realçam a imagem da cidade tradicional e são compartilhadas em todos os segmentos da população.

Esse argumento explica o porquê da ação de reconstrução dos casarões no mesmo lugar, pois a perda concreta do objeto simbólico da tradição fomentou uma reorganização no processo de identidade cultural dos citadinos. Instalou-se uma tensão no processo de autoqualificação da cidade - todo o acervo cultural lá existente era integrado à imagem concreta das edificações históricas - essas edificações eram a prova do tradicionalismo - político, religioso, cultural.

Partindo do pressuposto do corpo também como espaço, quando este se separa daquilo que também o constitui, ele não é mais visto como integrante do espaço representado, como se houvesse uma separação do humano e do lugar. O citadino abruptamente começa a ter um sentimento de desenraizamento em função da perda do lugar. Aqui aparece uma contradição dialética: não é mais o corpo que qualifica o espaço, mas o espaço que vai qualificar o corpo.

Em uma conversa com uma psicóloga voluntária no atendimento aos desabrigados, ela relatou, entre outras problemáticas, o adoecimento e falecimento de citadinos da cidade após a inundação. Aparentemente, os casos não tinham relação com a catástrofe, mas depois de alguns meses de observação ela tem percebido que essas problemáticas têm relação direta com o ocorrido.

Não encontramos nenhum levantamento quantitativo nesse sentido, mas temos como hipótese que as perdas materiais e imateriais ocasionadas pela enchente de 2009-20Io engendraram um estado psicológico nos vitimados de permanente tensão, suscitados entre outros aspectos pela tristeza e melancolia da perda, medo recorrente de uma nova enchente, desmotivação em função do tempo para reconstruir/adquirir novos objetos e imóvel, desorientação em função do conjunto de circunstâncias e acontecimentos caóticos na cidade entre outros.

Os relatos informais reafirmam nossa hipótese, pois indicam que alguns idosos que perderam a casa na enchente estão tendo quadro de crises emocionais, episódios depressivos, desenvolvendo doenças cardíacas e doenças respiratórias. Conjecturamos que essas pessoas, desesperançadas pela perda da casa, da igreja e outros objetos, não conseguiram sair de um quadro de tristeza e tensão que, segundo interlocutores do local, causou o falecimento de algumas.

Supomos que, na relação entre corpo e espaço, o sujeito psicológico vive enquanto seu corpo/espaço vive. Quando esse indivíduo perde espaços de compartilhamento, de afeto ou de memória, há uma propensão na população idosa de não resistir às mudanças, visto que o tempo e o corpo impõem barreiras para a inquietude de novas 
experiências. Nesse caso, em algumas pessoas permaneceu uma desesperança na sua visão de mundo, levando-as mesmo um quadro de desistência da vida. Como argumenta Berque, o que a qualifica como objeto é a existência do próprio homem que a vê, pois os objetos encarnam sentidos a partir da particularidade daquele que olha39. À guisa de exemplo, a queda da igreja matriz para alguns significou a perda mais profunda causada pela inundação, provocando uma tensão entre o modo de vida da população e a religiosidade. Afirmavam que a catástrofe foi castigo de Deus devido às festas pagãs (carnaval e festa do Saci) realizadas na cidade.

Assim, a tragédia tem um sentido particular para cada citadino de acordo com a história de vida na cidade. Contudo, mesmo havendo "fabricação" de espaços (representação do espaço), o concreto, o imaginário, se funde e se sobrepõe.

Nessa lógica, é possível uma síntese no sentido que a construção do espaço se deu pela transformação de um espaço integrado em espaço vivido, espaço de socialização. O espaço ocupado (de trabalho, de lazer, familiar) se define pelo movimento da atividade no próprio espaço social, visto que todo o "organismo vivo se reflete, se refrata nas modificações que produz em seu meio, seu ambiente, seu espaço”.".

\section{Conclusão}

O espaço de representação do centro urbano da cidade na qual se localizam a praça, o mercado e os casarões foi produzido historicamente nas mediações entre e o corpo e a cidade, e tais mediações fomentaram um modo de vida na cidade. A enchente, ao destruir parcialmente os objetos desse espaço provocou também um estado de tensão e desolamento dos vitimados, considerando que no espaço de representação as experiências: do corpo, da religiosidade, do simbolismo, estavam imbuídas de afeto, paixões, costumes e demarcações dos lugares. Quanto a este último item, os objetos demarcaram lugares representativos para os citadinos e esses espaços se correlacionaram ao tempo, às relações estabelecidas, às possibilidades, aos aspectos conjunturais.

O espaço concebido, ou a representação do espaço, é produzido nas estratégias de racionalização capitalista do espaço a partir de uma estratégia. Tem a ver com a ciência, com a lucratividade dos agentes que trabalham no espaço para transformá-lo em um fim. A representação do espaço, contudo, como pode ser demonstrado, domina e subordina o espaço de representação (de origem religiosa, cultural), reduzindo as figuras simbólicas a uma perspectiva, a uma imagem da cidade - um duplo real e aparente. No caso das edificações de São Luiz Paraitinga, esses elementos são conjugados e escondem contradições.

Para Lefebvre, o espaço social se manifesta para o sujeito como as interdições, os desejos, as fantasias, os signos, a linguagem, o sexo, o ritmo, as ideologias, os quais

39 BERQUE, Augustin. Laval théologique et philosophique. Philosophie japonaise du XXe siècle, vol. 64, n. 2, p. 327-344, jun. 2008.

40 LEFEBVRE, Henri. Op. cit., I974, s.p. 
são localizados no corpo e no espaço físico ${ }^{4 \mathrm{I}}$. A separação do corpo e da cidade, do eu e do corpo, produzida pela representação do espaço, deixa um interstício ocupado pela linguagem (discurso), pela divisão do trabalho, nos quais separam o vivido do saber, o real do aparente.

Nesse sentido, podemos supor que a representação do espaço modula modos de vida e cria cultura, pois, no nosso segundo acontecimento, as edificações destruídas novamente pela enchente serão reconstruídas no mesmo lugar. As duas grandes catástrofes registradas na cidade, a primeira em I863, a segunda em 2009-20I0, mesmo estando períodos históricos diferentes, em que as conjunturas sociais, políticas e econômicas mudaram no país, a ação do Estado e dos citadinos foi parecida: reconstrução no mesmo lugar.

Pareceu-nos que essa semelhança de ação dos agentes envolvidos (reconstrução) tem significados convergentes no que diz respeito ao domínio do Estado e aos interesses dos citadinos. Podemos afirmar uma coexistência do espaço de representação e da representação do espaço no contexto investigado, no qual permanecem resíduos históricos.

Para o Estado, a manutenção do centro histórico de forma semelhante se relaciona, a nosso ver, tanto no passado como no presente, com aspectos ligados à economia da cidade e ao simbolismo das edificações. Outrora, a construção dos casarões, no século XIX se relacionou ao período da produção cafeeira. Entretanto, no tempo presente, a cultura e as edificações históricas são elementos capitaneados pelo modo de produção turístico, base econômica atual da cidade.

Como diz Ana Carlos, o "turismo e lazer, enquanto atividades produtivas reproduzem lugares controlados, normatizados, homogêneos, dispostos de forma hierarquizada, impondo ritos, gestos, modelos que se articulam [...] expressando contradições entre o público e o privado entre o uso e a troca" 4 . Pautando-nos nesse postulado, as transformações produtivas que se irradiam e contradizem no espaço, são produtoras de sentidos, os quais fabricaram simulacros das edificações construídas, que para o Estado, funcionaram como estratégia de manutenção e controle socioeconômico e cultural.

Para os citadinos, a reconstrução perpassa também pelo econômico, mas o transcende, pois as edificações históricas são objetos da memória social ${ }^{43}$. Nela há as lembranças dos acontecimentos públicos e da vida privada, vinculados, ainda hoje, em um modo de vida tradicional, resíduo da vida caipira de outrora, conforme Candido bem definiu, uma vida com características ligadas à simplicidade, à tipologia da família, à propriedade da terra, ao tempo e às relações de vizinhança ${ }^{44}$.

Assim, o simbólico não se separou da espacialidade, mas a fez ressurgir como estratégia de manutenção dos aspectos sociais e culturais dos citadinos. A reconstrução pode ser interpretada como um mecanismo de restauração mínimo,

\footnotetext{
4I Idem. O espaço no fim de século: A nova raridade. São Paulo: Contexto, I999, p. 72.

43 HALBWACHS, M. A memória coletiva. 2. ed. São Paulo: Centauro, 20II.

44 CANDIDO, Antonio. Op. cit.
}

42 CARLOS, Ana Fani A. Novas contradições do espaço. In: DAMIANI, A. L.; CARLOS, A. F. A. e SEABRA, O. C. L. 
temporal, do equilíbrio psicológico dos vitimados. Reconstruir os objetos foi também manter uma memória social, uma estratégia para reorganizar, ressignificar e se motivar ao enfrentamento da situação caótica e abrupta a qual o citadino foi submetido.

Em São Luiz do Paraitinga, esse processo de construção da memória social emergiu na relação corpo/espaço/tempo, em um espaço social permeado por uma tradição judaico-cristã, pelo primado de aspectos da racionalidade capitalista e pelas forças produtivas. Compreender essa articulação possibilitou visualizar o sujeito social em seu aspecto global como materialidade percebida, vivida e concebida, e não como entidades parcelares (corpo, espaço, cidade).

Assim, destruiu-se a âncora do simulacro, mas a representação prescritiva no imaginário é tão forte que, em curto prazo, criou-se uma potência orientadora de um modo de vida. Como ressalta o jornalista, os citadinos vão empenhar-se na construção dos edifícios no mesmo lugar e a tragédia não sucumbirá à atividade turística desenvolvida no local.

Por fim, nas enchentes de I863 e 2009-20I0 as catástrofes provocaram um sentimento de solidariedade entre as pessoas, resgatando a relação do corpo/espaço e, ao mesmo tempo, explicitando as contradições do espaço social. Percebeu-se, nas duas catástrofes, um agenciamento produzido pelos órgãos públicos na condução do ideário da reconstrução. Tal ideário vem contribuindo para naturalizar a hierarquia espacial, fazendo parecer que o espaço é homogêneo - o centro político-administrativo representa toda a cidade, a imagem dele é a imagem da cidade. Por outro lado, a reconstrução, mesmo como cenário, parece ter produzido uma força simbólica que serve para elevar a autoestima dos habitantes da cidade, seu sentimento de pertencimento e sua esperança. 


\section{SOBRE OS AUTORES}

LEANDRO ROBERTO NEVES é professr do curso de Psicologia da Universidade Federal de Roraima (UFRR) e do Programa de Pós-graduação Sociedade e Fronteiras no Centro de Ciências Humanas da UFRR. Coordenou o curso de Psicologia da UFRR entre 20I3 e 2015 e presidiu a organização não governamental Terra Fértil em São Luiz do Paraitinga de 20II a 2013. Possui graduação em Psicologia e mestrado em Gestão e Desenvolvimento Regional, ambos realizados na Universidade de Taubaté. Fez doutorado em Psicologia Social pela Universidade de São Paulo. Tem experiência na área de Psicologia Social com ênfase em Política e Planejamento Governamentais, atuando principalmente nos seguintes temas: políticas públicas habitacionais, emergência e desastres, fronteira, cultura e representações da cidade.

IANNI REGIA SCARCELLI é professora do Departamento de Psicologia Social e do Trabalho do Instituto de Psicologia da Universidade de São Paulo. Orienta mestrado e doutorado em programa de pós-graduação, na área de concentração Psicologia Social, linha de pesquisa Política, Saúde Coletiva e Psicologia Social; mestrado profissional no Programa de Pós-graduação em Formação Interdisciplinar em Saúde. Pela Universidade de São Paulo, possui: graduação em Psicologia (I984), mestrado em Psicologia Social (I998) e doutorado em Psicologia Social (2002). Tem experiência na área de Psicologia, com ênfase em Psicologia Social e do Trabalho, atuando principalmente nos seguintes temas: psicologia social, saúde mental, saúde coletiva, políticas públicas e processos participativos. 


\section{REFERÊNCIAS BIBLIOGRÁFICAS}

ALMEIDA, Jaime de. Foliões: Festas em São Luís de Paraitinga na passagem do Século (I888-I9I8). Tese (Doutorado). São Paulo: Universidade de São Paulo, I987.

ARENDT, Hannah. A crise na cultura: Sua importância social e política. In: . Entre o passado e o

futuro. 6. ed. São Paulo: Perspectiva, 2007.

BACHELARD, Gaston. A poética do espaço. São Paulo: Martins Fontes, 2000.

BERQUE, Augustin. Laval théologique et philosophique. Philosophie japonaise du XXe siècle, vol. 64, n. 2, p. 327-344, jun. 2008.

. El pensamiento paisajero. Madri: Biblioteca Nueva, 2009. (Colección Paisaje y Teoría.)

. “Urbs Dat Esse Homini!" La trajectivité des formes urbaines. Conférence donnée au colloque Paisagem e arte, São Paulo, 6 septembre I999. In: ANGOTTI-SALGUEIRO (dir.). Paisagem e arte/ Paysage et art/ Paisaje y arte/Landscape and art. São Paulo: Comitê Brasileiro de História de Arte, 2000.

BETTANINI, Tonino. Espaço e ciências humanas. Rio de Janeiro: Paz e Terra, I982.

BOSI, Ecléa. Memória e sociedade: Lembranças de velhos. I6. ed. São Paulo: Companhia das Letras, 2010. BRANDÃO, Carlos R. Partilha da vida. São Paulo: Cabral Editora, I995.

CALVINO, Italo. As cidades invisíveis. São Paulo: Companhia das Letras, I972.

CANDIDO, Antonio. Os parceiros do Rio Bonito: Estudo sobre o caipira paulista e a transformação dos seus meios de vida. II. ed. Rio de Janeiro: Ouro Sobre Azul, 2010.

CARLOS, Ana Fani A. Novas contradições do espaço. In: DAMIANI, A. L.; CARLOS, A. F. A. e SEABRA, O. C.

L. O espaço no fim de século: A nova raridade. São Paulo: Contexto, I999.

COX, Harvey. A cidade do homem. 2. ed. Rio de Janeiro: Paz e Terra, I97I.

HALBWACHS, M. A memória coletiva. 2. ed. São Paulo: Centauro, 201 .

GONÇALVES, Bruno S. Na travessia da modernidade: Imaginação poética e resistência na memória de caipira em São Luiz do Paraitinga. Dissertação de mestrado. São Paulo: Pontifícia Universidade Católica, 2007.

LEFEBVRE, Henri. La production de l'espace. Paris: Anthropos, I974.

. A revolução urbana. 3. ed. Belo Horizonte: Editora UFMG, 2008.

LEITE, Maria Angela Faggin Pereira. Um sistema de espaços livres para São Paulo. Estudos Avançados, vol. 25, n. 7I, abr. 20II. Disponível em: 〈http://goo.gl/ItoOof〉. Acesso em: mar. 2016.

MASSEY, Doreen. Pelo espaço: Uma nova política da espacialidade. Rio de Janeiro: Bertrand Brasil, 2008.

NEVES, Leandro R. As trincheiras espaciais simbólicas: Circunscrevendo as políticas públicas habitacionais no Vale do Paraíba-SP. Anais do XIV Encontro Nacional da Abrapso, 2007. Disponível em: $\langle$ http://goo.gl/mjelsC $>$. Acesso em: mar. 2016.

PANKOW, Gisele. O homem e seu espaço vivido. Campinas: Papirus, I988.

SANTOS, João R. C. C. A Festa do Divino de São Luiz do Paraitinga: O desafio da cultura popular na contemporaneidade. Dissertação de mestrado. São Paulo: Universidade de São Paulo, 2008.

SENNETT, Richard. Carne e pedra: O corpo e a cidade na civilização ocidental. 4. ed..Rio de Janeiro: Record, 2006.

TOLEDO, Marcelo H. S. Espaços individuais e coletivos de sacralidade nos meios de populares: Um estudo sobre a imagem, conflitos simbólicos e campo religioso. Dissertação de mestrado. São Paulo: Pontifícia Universidade Católica, 2002.

TRINDADE, Jaelson B. No caminho do Paraitinga. In: TRINDADE, Jaelson B. Luis e SAIA, Luis. São Luiz do Paraitinga: Publicação n. 2 do Conselhos de Defesa do Patrimônio Histórico, Arqueológico, Artístico e Turístico do Estado. São Paulo, I977. 
TUAN, Yi Fu. Topofilia: um estudo da percepção, atitudes e valores do meio ambiente. Londrina: Eduel, 2012 VIEIRA, Luis A. “Está chegando o tempo de política... de eleição...”: Expressões da participação política dos moradores do Distrito de Catuçaba, São Luiz do Paraitinga, SP - Permanências e mudanças", 2007/2008. Dissertação de mestrado. São Paulo: Pontifícia Universidade Católica, 2008.

WIRTH, Louis. O urbanismo como modo de vida. In: VELHO, O. G. O fenômeno urbano. Rio de Janeiro: Zahar Editores, I967.

WUNENBURGER, Jean-Jacques. Imaginário e política. In: ARAÚJO, A. F. e BAPTISTA, F. P. (orgs). Variações sobre o imaginário: Domínios, teorizações e práticas hermenêuticas. São Paulo: Instituto Piaget, s.d. 